\title{
PRÁTICAS INFORMACIONAIS DOS DIRIGENTES DO SINDICATO DOS BANCÁRIOS DE BH E REGIÃO'
}

\author{
PRÁCTICAS INFORMATIVOS DEL DIRIGENTES SINDICALES DEL \\ SINDICATO DOS BANCÁRIOS DE BH E REGIÓN
}

\begin{abstract}
Dalgiza Andrade Oliveira - dalandrade@yahoo.com.br Doutora em Ciência da Informação pela Universidade Federal de Minas Gerais (UFMG). Docente da Universidade Federal de Alagoas (UFAL).

Maria Aparecida Moura - cidamoura@gmail.com Pós-doutora em Semiótica Cognitiva e Novas Mídias pela Maison de Sciences de I Homme. Docente da Escola de Ciência da Informação da Universidade Federal de Minas Gerais (UFMG).
\end{abstract}

\section{RESUMO}

Introdução: Os sindicatos são espaços em que a informação parece adquirir relevância a fim de municiar seus dirigentes, ativistas e militantes na defesa dos interesses dos trabalhadores por eles representados.

Objetivo: Caracterizar e analisar as práticas informacionais dos dirigentes do Sindicato dos Bancários de Belo Horizonte e Região.

Metodologia: $O$ estudo apoiou-se em abordagens teóricas que analisam a informação como um fenômeno social, a prática informacional e as transformações do mundo do trabalho. Para alcançar os objetivos propostos foi utilizada a técnica do grupo focal e entrevistas com os membros da diretoria do Sindicato.

Resultados: O estudo apontou para um alto índice de uso e preferência pelos recursos digitais e constatou também que o fato da entidade ter um Serviço de Informação Especializado contribui para a preparação dos dirigentes. Indicou ainda que a informação possui valor estratégico para os dirigentes e que a prática informacional é essencial à prática sindical.

\footnotetext{
${ }^{1}$ Este artigo é resultado de uma pesquisa realizada no PPGCI/UFMG.
} 
Conclusões: os dirigentes bancários no contexto do SEEB-BH são sindicalistas que possuem facilidade na relação com a informação e com as novas tecnologias. Compreendem a informação como necessária, indispensável e estratégica a sua prática sindical. Utilizam as ferramentas disponíveis e acessíveis a partir dos meios eletrônicos com facilidade e assiduidade.

Palavras-chave: Informação. Prática informacional. Prática sindical. Bancários. Sindicatos. Mundo do trabalho. Processo de trabalho bancário.

"Uma das questões centrais com que temos de lidar é a promoção de posturas rebeldes em posturas revolucionárias que nos engajam no processo radical de transformação do mundo. A rebeldia é o ponto de partida indispensável, é a deflagração da justa ira, mas não é suficiente. A rebeldia enquanto denúncia precisa se alongar até uma posição mais radical e crítica, a revolucionária, fundamentalmente anunciadora. A mudança no mundo implica a dialetização entre a denúncia da situação desumanizante e o anúncio de sua superação; no fundo, o nosso sonho."

Paulo Freire

\section{INTRODUÇÃO}

$\mathrm{Na}$ atualidade, a informação como objeto de estudo, tem sido tema recorrente. Nesse sentido, pensar a informação no contexto da atividade sindical torna-se desafiador a partir da proposição de estudo das práticas de informação que ocorrem neste contexto. Os sindicatos são espaços em que a informação parece adquirir relevância a fim de municiar seus dirigentes, ativistas e militantes na defesa dos interesses dos trabalhadores por eles representados.

$\mathrm{Na}$ sua conexão com a Ciência da Informação, este estudo procurou se embasar na perspectiva de compreender a informação como um fenômeno social. A ênfase se deu na identificação das práticas informacionais operadas pelos dirigentes do Sindicato dos Empregados em Estabelecimentos Bancários de Belo Horizonte e Região (SEEB-BH), na consecução de suas práticas sindicais.

No contexto da prática sindical, a informação parece ser fundamental, pois subsidia as ações desenvolvidas por seus dirigentes. Sendo assim, adquire ela um papel essencial, pois está presente nos mais variados aspectos da vida do cidadão: desde seu processo cognitivo mais remoto até seu reconhecimento na vida em sociedade, a partir dos registros identificadores de sua existência civil, tangenciada.

No que se refere ao mundo do trabalho, o fenômeno informacional também está presente, tendo em vista que as transformações ocorridas neste meio estão 
associadas, sobretudo, ao desenvolvimento tecnológico e, conseqüentemente, à propagação e à utilização dos recursos informacionais disponíveis.

Nessa perspectiva, por meio da interação social desenvolvem-se ações sociais que podem advir de várias origens. O Sindicato pode ser um espaço que promova a interação e também a representação a partir dos instrumentos que dispõe para a mobilização dos seus representados.

No que diz respeito às práticas informacionais, elas podem se constituir com um elemento de apoio essencial as ações políticas. Ela ainda é determinada pelo pertencimento cultural, político e social. Já no que se refere à prática sindical, esta é organizada para fazer face ao ordenamento do mundo do trabalho que também possui uma prática informacional determinada pelo pertencimento.

$\mathrm{Na}$ sua relação com a prática sindical e o trabalho, a prática informacional evidencia uma disputa que se dá entre o capital $x$ trabalho, empregador $x$ trabalho, dirigente sindical $x$ empregador nas suas relações. Ao evidenciar tais antagonismos, os dirigentes sindicais bancários se viram na contingência de aprimorar e qualificar a ação sindical por meio do uso estratégico da informação.

Pressupõe-se que a apropriação da informação pode contribuir para a construção de conhecimento sobre determinados conteúdos, selecionados ou recebidos espontaneamente.

$\mathrm{Na}$ discussão do processo sócio histórico, a informação pode adquirir uma feição portadora de identidade, notadamente, no que se refere à formação das coletividades. Sendo assim, os sindicatos são espaços sociais em que as manifestações dos sujeitos envolvidos no seu contexto têm expressão e lugar. Deste modo, o fluxo informacional que ocorre neste espaço pode ser intenso e dar suporte à mobilização e às ações dos ativistas. Neste aspecto, a luta sindical se vale centralmente do grau de informação que adquire, inclusive possibilitando o surgimento de lideranças informacionais que podem ser entendidas como pessoas chaves na organização. Nesta relação é possível identificar também a ocorrência de práticas informacionais.

\section{INFORMAÇÃO, MUNDO DO TRABALHO E PRÁTICA SINDICAL BANCÁRIA}


A informação tem sido objeto de muitos estudos em diferentes contextos. Parte-se da idéia de que a informação é uma construção social, no sentido de que os sujeitos sociais inseridos num determinado contexto sócio-histórico e, a partir de uma determinada situação, atribuem sentido a ela. Essa situação poderá transformar a consciência bem como o contexto (ARAÚJO, 1998).

$\mathrm{Na}$ prática sindical, o acesso à informação e, conseqüentemente, aos seus conteúdos, poderá servir de instrumento estimulador às ações e lutas empreendidas pelas entidades ou, em contraposição, o não acesso poderá encaminhar ao arrefecimento do movimento sindical. Sendo assim, concorda-se com Brookes (1980) quando afirma que a informação é um elemento que provoca transformações nas estruturas, pois gera novos estados de conhecimento.

A informação pode ser entendida, também, como instituinte socializador, já que é parte de um processo de comunicação que envolve etapas como a emissão, transmissão e recepção de uma determinada mensagem. Ela é produzida pela sociedade em alguns de seus extratos ou grupos. Para Cardoso (1996, p. 72) "a informação é uma prática intersubjetiva [...] se constitui na energia de um processo auto-gerativo de acercamento do saber." Neste aspecto, a informação adquire importância na medida em que grupos e/ou indivíduos necessitem dela.

Os sindicatos podem ser espaços facilitadores da interação social, propiciando trocas a partir do fornecimento e do recebimento de conteúdos informacionais. A instituição sindical trabalha essencialmente com a defesa de interesses de seus representados e, neste aspecto, vai se dedicar a fazer com que a manutenção destes interesses prevaleça. Uma das formas de atuação é por meio do desenvolvimento de ações políticas, que de acordo com Araújo (2000, p. 4), "tanto podem criar a possibilidade de transformação progressiva da sociedade, a partir de certos valores; como também pode gerar a possibilidade de manutenção das estruturas existentes".

A informação é também uma construção social. Contudo, ela, por si só, não é uma prática. Wersig (1985), tendo como base a realidade social, considera que as práticas informacionais acontecem sempre entre indivíduos duplamente geradores e receptores de informação, a partir de um 'equipamento prévio' que os capacita para a comunicação e para a ação. Práticas são ações realizadas por sujeitos socialmente posicionados que se baseiam no uso da informação. Dessa forma, as práticas informacionais são na compreensão de Araújo (1998, p. 2), "ações de 
recepção, geração e transferência de informação que se desenvolvem através de circuitos comunicacionais ocorridos nas formações sociais".

\section{O TRABALHO E O PROCESSO DE TRABALHO BANCÁRIO}

O ambiente de trabalho de funcionários de instituições financeiras tem passado, ao longo dos últimos trinta anos, por diversas transformações. A volatilidade no trabalho tem sido uma constante.

O desenvolvimento tecnológico tem sido propulsor destas mudanças, notadamente no que diz respeito à implantação da automação bancária. Outro fator de mudança operado no mundo do trabalho bancário relaciona-se com a reestruturação produtiva ${ }^{2}$.

Para Navarro (2004), no Brasil, a incrementação do processo de reestruturação produtiva data das três últimas décadas, em meio aos rumos tomados pela globalização da economia brasileira, pois esta passa a se abrir para o capital internacional. Essa situação é uma das decorrências do neoliberalismo que segundo Anderson (1995, p. 14):

[...] é um movimento ideológico, em escala verdadeiramente mundial, como o capitalismo jamais havia produzido no passado. Trata-se de um corpo de doutrina coerente, autoconsciente, militante, lucidamente decidido a transformar todo o mundo à sua imagem, em sua ambição estrutural e sua extensão internacional.

Os estabelecimentos bancários no Brasil, conjuntamente com o setor automobilístico, foram pioneiros na promoção da reestruturação produtiva nos seus processos de trabalho.

Para a categoria bancária, as inovações tecnológicas e, por conseguinte, a automação bancária têm sido desafiadoras, pois a ameaça do desemprego tem se configurado como uma constante. No processo de trabalho bancário muitas atividades foram gradualmente substituídas ou até mesmo extintas. Blass (1989) acentua que as modificações que transcorreram no processo de trabalho bancário pressupõem também uma gradativa expropriação do saber técnico dos trabalhadores, transformando a própria visão do trabalho efetuado.

\footnotetext{
${ }^{2}$ Para Filgueiras (1997), a reestruturação produtiva pode ser compreendida como uma resposta do capital à queda/estagnação da produtividade e à diminuição dos lucros.
} 
A terceirização é um aspecto decorrente deste processo de reestruturação. Contribui, também, para a diminuição dos postos de trabalho a expansão da internet e as transações em rede. Poucas são as transações financeiras que não podem ser efetuadas por este meio. Em geral são aqueles serviços bancários que requerem observância na cobrança de juros e correção monetária.

Diante de tantas alterações ocorridas no trabalho bancário, como tem sido a resposta do ponto de vista da organização sindical destes trabalhadores? Parece haver no interior do movimento sindical certa constatação de que se está diante de um período de refluxo de lutas. Entretanto, as demandas dos trabalhadores exigem que os sindicatos se posicionem. Compreende-se que a prática sindical é a parte operante da estrutura sindical, entendida aqui, como um grupo de normas de funcionamento bem como de organização dos sindicatos (GIANNOTTI, 1987).

A prática sindical não deve estar dissociada da defesa permanente dos interesses dos trabalhadores. Diante destas abordagens, é importante compreender o contexto das forças sociais e políticas atuantes e intervenientes na configuração das práticas informacionais do dirigente sindical bancário, bem como o papel histórico que os sindicatos têm e qual a sua relação com a informação.

\section{O SINDICATO DOS BANCÁRIOS DE BELO HORIZONTE E REGIÃO}

Os sindicatos são instituições criadas a fim de defender os interesses dos trabalhadores perante os empregadores. Estes interesses podem ser de ordem econômica e social. Os sindicatos são para Bottomore (1988, p. 334), "associações de trabalhadores da mesma ocupação ou do mesmo ramo de indústria".

O SEEB-BH foi criado em 1932 e, atualmente, a sua base territorial abarca 152 (cento e cinqüenta e duas) cidades, possui em seus registros cerca de 7.800 (sete mil e oitocentos) filiados, conta com 50 (cinqüenta) diretores. A categoria é de aproximadamente 13.200 bancários (treze mil e duzentos) na base territorial do sindicato (os bancários estão distribuídos em 1.787 agências).

No decorrer de sua trajetória profissional, a categoria bancária vem sendo protagonista de inúmeras transformações no seu processo de trabalho e, de certo modo, a mesma acaba sendo acometida irremediavelmente de perdas significativas no que se refere aos postos de ocupação. 
Este quadro de constante mutabilidade verificada na categoria tem exigido por parte das entidades representativas dos bancários, no caso, os sindicatos, muito trabalho no que diz respeito à defesa dos interesses de seus filiados. Estes desafios são de toda ordem, inclusive no que se refere ao domínio de conteúdos informacionais, pois os ativistas, militantes e dirigentes deste segmento têm que estar bem instrumentalizados e preparados para enfrentar estas demandas colocadas pelas mudanças.

\section{PRÁTICA INFORMACIONAL E PRÁTICA SINDICAL}

O dirigente sindical na sua ação cotidiana necessita se municiar de informações para estar inteirado do que acontece a sua volta. O caráter estratégico da informação adquire assim importância fundamental, pois a partir da disponibilidade das fontes e das práticas informacionais operadas, a ação sindical pode se valer destes mecanismos. Para tanto, os conteúdos informacionais precisam ser explorados a fim de contribuírem para o combate à alienação.

Este tipo de ação do Sindicato é muito identificado com a idéia de prática cidadã e, desta forma, a informação deve ser olhada como um bem social e um direito coletivo como os demais, sendo tão importante como o direito à educação, à saúde, à moradia, à justiça, dentre outros (ARAúJJO, 1999).

Tornar a informação acessível passa a ser então uma necessidade e, neste aspecto, quando o dirigente parte para o campo de ação necessita estar bem informado a fim de poder disputar, em nível de igualdade, com seu empregador, os direitos que the devem ser assegurado.

Em consonância com Berger e Luckmann (1996), o acervo social do conhecimento inclui o conhecimento da própria situação do individuo e de seus limites, e este conhecimento é partilhado, permitindo a localização dos indivíduos na sociedade e no manejo deles de maneira apropriada. Assim, se o sujeito tem conhecimento de sua realidade social, terá condições de se comunicar e de agir.

Sendo assim, ao se pensar a ação sindical e, por conseqüência, sua prática, é preciso destacar que as práticas informacionais da categoria bancária podem incidir sobre os rumos que o movimento sindical bancário poderá tomar e sobre as respostas que poderá apresentar no nível da ação sindical. 
Ao se definir pelo estudo dos Serviços de Informação do SEEB-BH, a intenção desse estudo foi caracterizar e analisar as práticas informacionais dos dirigentes, com a finalidade de compreender o papel da informação nas ações sindicais. O estudo procurou investigar o papel da informação na prática do dirigente da categoria bancária. Sendo assim, dedicou-se ainda na identificação das necessidades informacionais desses dirigentes para o exercício da ação sindical. Para tanto se fez necessário caracterizar as estratégias adotadas pelos mesmos na identificação e seleção das informações necessárias à prática sindical e, ainda, identificar o uso de serviços especializados de informação como suporte ao processo de tomada de decisão do dirigente com vistas aos fóruns deliberativos da categoria.

\section{OS SERVIÇOS DE INFORMAÇÃO DO SINDICATO}

A implantação do Centro de Referência e Memória Sindical (CRMS) do SEEB-BH foi em 1997 e possibilitou que a entidade reorientasse sua ação na relação com a informação. Desta forma, o Centro contribuiu para que se apontassem definições acerca de políticas de fluxos informacionais.

Os serviços de informação do SEEB-BH estão assim distribuídos:

- Site do Sindicato dos Bancários de Belo Horizonte e Região http://www.bancariosbh.org.br/: site do sindicato na internet que disponibiliza conteúdos da entidade e da categoria.

- Babilônia Sindical (intranet): página interna do sindicato que disponibiliza alguns bancos de dados, informações sobre filiados, correio eletrônico, biblioteca virtual, acervo fotográfico digitalizado e indexado.

- Acervo Documental: constituído por documentos arquivísticos, livros, publicações periódicas, documentos fotográficos e audiovisuais. Há ainda os dossiês temáticos que são constituídos a partir de temas de interesse da entidade e da categoria.

O CRMS conta com uma equipe de trabalho composta por um bibliotecário, um analista de informática e dois estagiários. As atividades são acompanhadas e monitoradas pelo Diretor de Pesquisa do Sindicato, uma vez que o CRMS está alocado neste departamento. $\mathrm{O}$ trabalho desenvolvido no Centro é acompanhado, ainda, pela direção do Sindicato. 
O acesso aos Serviços de Informação oferecidos pelo CRMS é aberto aos usuários internos, ou seja, diretores e funcionários. Em se tratando de usuários externos como bancários, outras entidades sindicais e pesquisadores, o atendimento é realizado mediante solicitação prévia.

\section{A PERCEPÇÃO dOS DIRIGENTES SOBRE A INFORMAÇÃO, PRÁtICA SINDICAL, TECNOLOGIA E PRÁTICA INFORMACIONAL}

A pesquisa foi realizada com a Diretoria Executiva do SEEB-BH e Região composta por doze diretores em universo de cinqüenta. A faixa etária variou dos 30 aos 50 anos, com média em torno dos 35 anos. A maioria possuía curso superior.

Foi parte da pesquisa formular questões que visassem à percepção dos dirigentes sindicais bancários sobre as principais atividades relacionadas à ação sindical desenvolvidas pelo Sindicato; a percepção dos dirigentes em relação às principais atividades relacionadas à ação sindical desenvolvidas por eles; a compreensão dos dirigentes acerca da informação e de seu valor estratégico; do relacionamento com as novas tecnologias de informação e comunicação, e a percepção sobre prática sindical.

Nas situações determinadas em que envolviam processos de tomada de decisão foi formulada questão sobre quais os mecanismos utilizados, conhecimento sobre os recursos de informação disponíveis no SEEB-BH e a utilização desses recursos.

Nos recursos informacionais disponibilizados pela Intranet, foi consultado aos entrevistados quais eram os mais utilizados. Tendo em vista que nos Serviços de Informação do SEEB-BH existem documentos em formato digital e impresso, foi então formulada questão sobre a preferência dos dirigentes sobre os dois tipos. Esgotadas as questões relacionadas aos Serviços de Informação disponibilizados pelo Sindicato foi então formulada uma questão sobre outras fontes de informação utilizadas por estes dirigentes.

\section{RELAÇÃO COM A PRÁTICA INFORMACIONAL}

A prática informacional é entendida aqui como aquisição de informação, divulgação, atualização, busca, troca, reprodução. Os depoimentos dos dirigentes vão de acordo à definição de Araújo (1998, p. 2) quando fala que práticas 
informacionais são "ações de recepção, geração e transferência de informação que se desenvolvem através de circuitos comunicacionais ocorridos nas formações sociais".

A prática sindical dos dirigentes do SEEB-BH tem revelado que para a sua execução de forma a atender minimamente aos anseios da categoria é necessário que ele se valha de práticas informacionais. Desta forma, os dirigentes ao tomarem conhecimento da informação, podendo articular os fatos que lhes sejam relevantes e, principalmente, disseminá-las estão dando seqüência ao circuito informacional necessário aos processos de comunicação que devem existir nos grupos sociais. Isso vai ao encontro da importância que se deve dar ao processo de democratização da informação principalmente no âmbito dos movimentos sociais.

\section{CONSIDERAÇÕES FINAIS}

Esta investigação procurou estabelecer as relações existentes entre práticas informacionais e práticas sindicais no contexto do Sindicato dos Bancários de Belo Horizonte e Região mediante a ação de seus dirigentes.

A condição de usuários de informação que também têm os dirigentes sindicais bancários, assim como outras categorias de usuários da informação, adquire uma centralidade significativa para a Ciência da Informação. Isto se dá em função de que esta se dedica aos estudos de uso de informação em contextos específicos. Neste sentido, este trabalho procurou compreender práticas informacionais e sindicais como um fenômeno social, no âmbito dos estudos relativos à informação.

Esse trabalho buscou ainda contribuir com o campo da Ciência da Informação, tentando demonstrar que é necessário se enveredar por segmentos sociais específicos a fim de identificar o que o estudo da informação revela. Podendo estudos dessa natureza contribuir de forma vigorosa para a área.

No vínculo entre as práticas informacionais e as práticas sindicais foi possível detectar que é condição fundamental para a ação sindical a ocorrência de práticas informacionais. Desta forma, procurou-se evidenciar que as práticas informacionais estão presentes na prática sindical empreendida pelos dirigentes do SEEB-BH. 
Nos dados colhidos entre os entrevistados foi possível perceber ocorrência de práticas informacionais operadas no interior do Sindicato, a partir das ações dos seus dirigentes na sua relação com os serviços de informação, em contato com seus filiados mediante suas práticas sindicais.

A informação para o sindicalista é relevante inclusive no que se refere à forma como organiza e orienta sua prática sindical. Esta situação se apresenta, por exemplo, nos fóruns deliberativos da categoria quando decisões importantes são encaminhadas. Nesses processos que envolvem tomadas de decisão, os dirigentes buscam suas fontes de informação tanto nos serviços disponíveis como os que são oferecidos pelo CRMS quanto nos canais informais.

Pode-se inferir que a informação tem valor estratégico para os dirigentes que se municiam e se nutrem dela para sua ação sindical. Desta forma, observa-se que estes dirigentes podem ser reconhecidos pela categoria como lideranças informacionais.

Os entrevistados possuem facilidade para manusear os recursos eletrônicos e os acessam com relativa freqüência. E, em relação ao uso das fontes de informação, os dirigentes, na sua maioria, manifestam maior preferência pelas fontes em formato digital. Por outro lado, ainda há muita pesquisa nas fontes impressas em função de alguns documentos que estão sob este formato. Entretanto, estes itens documentais são indispensáveis principalmente para o setor administrativo do Sindicato.

Os dirigentes apontam disseminação da informação como atividade importante à prática sindical, contudo, ressaltam como principais atividades a luta por melhores condições de trabalho, a representatividade, defesa dos direitos e a campanha salarial da categoria. Neste sentido, se fundamentam em informações relativas à conjuntura sindical e política que são obtidas nas fontes disponíveis. Atribuem aos contatos interpessoais e a outros organismos representativos da categoria grande relevância para obterem informações para o desempenho de sua ação sindical.

A partir das questões que envolvem o conhecimento dos entrevistados sobre os recursos informacionais disponíveis no Sindicato, pôde-se constatar que o fato da entidade dispor de um Serviço de Informação Especializado contribui para a preparação política e informacional dos dirigentes. Desta forma, com programas de treinamento permanente, é possível possibilitar a esses sindicalistas manuseio e facilidade de acesso às fontes disponíveis. 
A categoria bancária vem passando ao longo dos últimos trinta anos por diversas transformações que alteram o cotidiano do seu processo de trabalho. Sendo assim, para os dirigentes sindicais é fundamental estar acompanhando essas transições, pois necessitam do ponto de vista da ação sindical, dar respostas que possam contribuir no fortalecimento da categoria.

Os dados coletados apontam na perspectiva de estudos futuros tendo em vista que a investigação realizada se estruturou em apenas uma entidade. Neste sentido, o segmento estudado é componente de um setor da sociedade brasileira, no caso o movimento sindical, que no sentido mais amplo mereceria maiores pesquisas a fim de contribuir para a emancipação de seus atores na superação de dificuldades referentes às demandas informacionais decorrentes do contexto do sindicalismo.

Diante dos objetivos propostos para esse estudo que eram: investigar o papel da informação na prática do dirigente sindical da categoria bancária; identificar as necessidades informacionais dos dirigentes sindicais para o exercício da ação sindical; caracterizar as estratégias adotadas pelos dirigentes sindicais na identificação e seleção das informações necessárias à prática sindical e Identificar o uso de serviços especializados de informação como suporte ao processo de tomada de decisão do dirigente sindical em vista aos fóruns deliberativos da categoria, entende-se que foram atingidos. Espera-se que os resultados obtidos possam contribuir para um maior e melhor entendimento dos vínculos entre prática sindical e prática informacional.

Por último, concluí-se que os dirigentes bancários no contexto do SEEB-BH são sindicalistas que possuem facilidade na relação com a informação e com as novas tecnologias. Compreendem a informação como necessária, indispensável e estratégica a sua prática sindical. Utilizam as ferramentas disponíveis e acessíveis a partir dos meios eletrônicos com facilidade e assiduidade. Embora alguns dirigentes identifiquem que as novas tecnologias trouxeram o problema do desemprego para a categoria, entendem, por outro lado, que é inexorável a sua afirmação e adoção pela sociedade. Apesar das facilidades mediante os contatos virtuais concebem a prática sindical militante no local de trabalho, no contato com o representado indispensável, e, nesse sentido, compreendem a prática informacional como elemento vital para o êxito de suas ações. 


\section{REFERÊNCIAS}

ANDERSON, Perry. Balanço do neoliberalismo. In: SADER, Emir; GENTILI, Pablo. Pós-neoliberalismo: as políticas sociais e o Estado democrático. Rio de Janeiro: Paz e Terra, 1995. p. 9-23.

ARAÚJO, Eliany Alvarenga de. A construção social da informação: práticas informacionais no contexto de organizações não-governamentais/ONGs brasileiras. 1998. 221 f. Tese (Doutorado em Ciência da Informação) - Faculdade de Estudos Sociais Aplicados, Universidade de Brasília, Brasília, 1998.

. Informação, sociedade e cidadania: gestão da informação no contexto de organizações não-governamentais (ONGs) brasileiras. Ciência da Informação, Brasília, v. 29, n. 2, p. 155-167, maio/ago. 1999.

. Informação: recurso para a ação política do cidadão? Encontros Bibli: Revista Eletrônica de Biblioteconomia e Ciência da Informação, Florianópolis, n. 9, jun. 2000. Disponível em: <http://www.ced.ufsc.br/bibliote/encontro/>. Acesso em: 10 out. 2004.

BERGER, Peter; LUCKMANN, Thomas. A construção social da realidade. 13. ed. Petrópolis: Vozes, 1996.

BLASS, Leila Maria da Silva. O trabalho bancário: o (re) fazer de todo instante. Cadernos de Formação, São Paulo, n. 2, p. 20, 1989.

BOTTOMORE, Tom (Ed). Dicionário do pensamento marxista. Rio de Janeiro: Zahar, 1988.

BROOKES, Bertram C. The foundations of information science - part I: philosphical aspects. Journal of Information Science, Northants, n. 2, p. 125-133, 1980.

CARDOSO, Ana Maria Pereira. Pós-modernidade e informação: conceitos complementares? Perspectivas em Ciência da Informação, Belo Horizonte, v. 1, n. 1, p. 63-79, jan./jun. 1996.

FILGUEIRAS, Luiz A. M. Reestruturação produtiva, globalização e neoliberalismo: capitalismo e exclusão social neste final de século. In: SEMINÁRIO

INTERDISCIPLINAR "O MAL-ESTAR NO FIM DO SÉCULO XX”, 1997, Bahia.

Anais... Bahia: Universidade Estadual de Feira de Santana, Escola Brasileira de Psicanálise, 1997. Disponível em:

<http://www.cefetsp.br/edu/eso/globalizacao/neoglobliberalismo.pdf>. Acesso em: 22 maio 2008. 
GIANNOTI, Vítor. A liberdade sindical no Brasil. 2. ed. São Paulo: Brasiliense, 1987.

NAVARRO, Vera Lúcia. A reestruturação produtiva na indústria de calçados de couro em Franca (SP). In: ANTUNES, Ricardo; SILVA, Maria Aparecida Moraes (Org.). O avesso do trabalho. São Paulo: Expressão Popular, 2004, p. 79-152.

SINDICATO DOS BANCÁRIOS DE BELO HORIZONTE E REGIÃO. Disponível em: <http://www.bancariosbh.org.br/>. Acesso em: 12 jan. 2004.

WERSIG, Gernot; WINDEL, G. Information science needs a theory of information actions. Social Science Information Studies, Kent, v. 5, n. 1, p. 11-23, Jan. 1985.

Title

Manager's informational practices from sindicato dos bancários de $\mathrm{BH}$ e region

Abstract:

Introduction: The unions are spaces where information seems to acquire relevance to munition its leaders, activists and advocates in the interests of the workers they represent.

Objective: To characterize and analyze the information practices of the leadership of the Union of Bank Employees and Region of Belo Horizonte.

Methodology: The study was based on theoretical approaches that analyze information as a social phenomenon, the practice informational and changes in the world of work. To achieve the objectives proposed technique was used the focus group and interviews with board members of the Syndicate.

Results: The study pointed to a high use and preference for digital resources and found that the fact of the entity have a Specialized Information Services contributes to the preparation of leaders. He indicated that the information has strategic value for the leaders and the informational practice is essential to the practice of association.

Conclusions: banking leaders in the context of SEEB-BH are unionists who have facility in relationship to information and new technologies. Comprise the information as necessary, indispensable and strategic practice their union. Use the tools available and accessible from the electronic media with ease and assiduity.

Keywords: Information. Informational practice. Union trade practice. Bank clerks. Unions. Work World. Process of banking work.

\section{Titulo}

Prácticas informacionales de los dirigentes del sindicato de los bancarios de BH y región

\section{Resumen:}

Introducción: Los sindicatos son espacios en los que la información parece adquirir relevancia a fin de municionar sus dirigentes, activistas y militantes en la defensa de los intereses de los trabajadores por ellos representados. 
Objetivo: Caracterizar y analizar las prácticas informacionales de los dirigentes del "Sindicato dos Bancários de Belo Horizonte e Região".

Metodología: El estudio está basado en abordajes teóricos que analizan la información como fenómeno social, la práctica informacional y las transformaciones del mundo del trabajo. Para alcanzar los objetivos propuestos fue utilizada la técnica del grupo focal y entrevistas con los miembros de la junta directiva del Sindicato.

Resultados: El estudio señaló un alto índice de uso y preferencia por los recursos digitales y constató también el hecho de que la entidad tiene un Servicio de Información Especializado que contribuye para la preparación de los dirigentes. Indicó, además, que la información posee valor estratégico para los dirigentes y que la práctica informacional es esencial a la práctica sindical.

Conclusiones: Los dirigentes bancarios en el contexto del SEEB-BH son sindicalistas que poseen facilidad en la relación con la información y con las nuevas tecnologías. Comprenden la información como necesaria, indispensable y estratégica para su práctica sindical. Utilizan las herramientas disponibles y asequibles a partir de los medios electrónicos con facilidad y asiduidad.

Palabras clave: Información. Práctica informacional. Práctica Sindical. Bancarios. Sindicatos. Mundo del trabajo. Proceso de trabajo bancario.

Recebido em: 13.07.2012

Aceito em: 10.05.2013 